\title{
Persistent Ischemic Stroke Disparities despite Declining Incidence in Mexican Americans
}

\author{
Lewis B. Morgenstern, MD, 1,2,3 Melinda A. Smith, DrPh, ${ }^{1}$ Brisa N. Sánchez, PhD, ${ }^{4}$ \\ Devin L. Brown, MD, MS, ${ }^{1}$ Darin B. Zahuranec, MD, MS, ${ }^{1}$ Nelda Garcia, BS, ${ }^{1}$ \\ Kevin A. Kerber, MD, MS, ${ }^{1}$ Lesli E. Skolarus, MD, MS, ${ }^{1}$ William J. Meurer, MD, \\ $\mathrm{MS}^{1,2}$ James F. Burke, MD, MS, ${ }^{1,5}$ Eric E. Adelman, MD, ${ }^{1}$ Jonggyu Baek, MS, ${ }^{4}$ \\ and Lynda D. Lisabeth, $\mathrm{PhD}^{1,3}$
}

\begin{abstract}
Objective: To determine trends in ischemic stroke incidence among Mexican Americans and non-Hispanic whites. Methods: We performed population-based stroke surveillance from January 1, 2000 to December 31, 2010 in Corpus Christi, Texas. Ischemic stroke patients 45 years and older were ascertained from potential sources, and charts were abstracted. Neurologists validated cases based on source documentation blinded to ethnicity and age. Crude and age-, sex-, and ethnicity-adjusted annual incidence was calculated for first ever completed ischemic stroke. Poisson regression models were used to calculate adjusted ischemic stroke rates, rate ratios, and trends.

Results: There were 2,604 ischemic strokes in Mexican Americans and 2,042 in non-Hispanic whites. The rate ratios (Mexican American:non-Hispanic white) were 1.94 (95\% confidence interval $[\mathrm{Cl}]=1.67-2.25), 1.50(95 \% \mathrm{Cl}=1.35-$ 1.67), and $1.00(95 \% \mathrm{Cl}=0.90-1.11)$ among those aged 45 to 59,60 to 74 , and 75 years and older, respectively, and $1.34(95 \% \mathrm{Cl}=1.23-1.46)$ when adjusted for age. Ischemic stroke incidence declined during the study period by $35.9 \%(95 \% \mathrm{Cl}=25.9-44.5)$. The decline was limited to those aged $\geq 60$ years, and happened in both ethnic groups similarly $(p>0.10)$, implying that the disparities seen in the 45- to 74-year age group persist unabated.

Interpretation: Ischemic stroke incidence rates have declined dramatically in the past decade in both ethnic groups for those aged $\geq 60$ years. However, the disparity between Mexican American and non-Hispanic white stroke rates persists in those $<75$ years of age. Although the decline in stroke is encouraging, additional prevention efforts targeting young Mexican Americans are warranted.
\end{abstract}

ANN NEUROL 2013;74:778-785

$\mathrm{M}$ exican Americans (MAs) are the most numerous segment of Hispanic/Latinos, the United States' largest minority population. Now comprising $16.7 \%$ of the population, Hispanic/Latinos will make up $>30 \%$ of the United States by $2050 .{ }^{1}$ We previously reported that MAs have higher stroke rates compared with nonHispanic whites (NHWs) using the population-based Brain Attack Surveillance in Corpus Christi (BASIC) study. ${ }^{2}$ After a decade of observation, we can now pro- vide data comparing temporal trends in ischemic stroke incidence in MAs and NHWs. As the youthful MA population ages and becomes more numerous, these data have critical public health importance in addressing the personal, family, and societal impact of stroke. A recent estimate of the cost of stroke for the first half of the $21 \mathrm{st}$ century suggested a staggering price tag of $\$ 1.52$ trillion, ${ }^{3}$ approximately equal to 1 year of the US gross tax revenue. ${ }^{4}$ The cost of stroke is significantly higher in 
minority populations, where stroke occurs at younger ages and with greater resulting disability. ${ }^{2,5}$

Health disparity reduction efforts by definition seek to narrow the gap of disease burden borne by minority populations compared with majority populations. Monitoring the trends in common, severe, and expensive diseases, such as stroke, is critical to understanding the progress toward this goal. Declines in ischemic stroke incidence have been suggested throughout the world previously, ${ }^{6-12}$ but contemporary community-based studies that include diverse US populations are lacking. The current study used rigorous, continuous stroke case ascertainment within a biethnic community to calculate ischemic stroke rates among MAs and NHWs over the years 2000-2010. The goal was to determine trends over time comparing the 2 ethnic populations.

\section{Subjects and Methods}

This is the primary, prespecified analysis resulting from specific aim 1 of BASIC. The project's methods were previously published. 2,13,14 They are briefly summarized here.

\section{Patients and Setting}

BASIC takes place in Nueces County, Texas, a predominantly urban location, where $95 \%$ of the population resides in the city of Corpus Christi on the Texas gulf coast; approximately $2 / 3$ are MAs and the remainder are predominantly NHWs. ${ }^{15}$ This is a nonimmigrant community, with the majority of residents second- and third-generation US citizens. ${ }^{16}$ The usual routes through Texas take immigrants from the southern Texas border cities of McAllen, Harlingen, and Brownsville to San Antonio, Houston, and Dallas. ${ }^{17}$ Overall, $\ll 5 \%$ of Nueces County residents are undocumented, ${ }^{18}$ and this is true of an even smaller percentage of those 45 years of age and older, which is BASIC's target population. In a sample of BASIC participants who underwent interview, $86.9 \%$ were born in the United States, $10.5 \%$ were born in Mexico, $1.4 \%$ did not know their country of birth, $1 \%$ were born in another country, and $0.2 \%$ refused to answer the question. Of those born in Mexico, the average years of residence in the United States was 52.2 years $(\mathrm{SD}=$ 18.0; minimum $=13$; median $=51$ ).

Corpus Christi is approximately 150 miles from potential referral centers in San Antonio and Houston, and the adjacent counties are sparsely populated. This distance and geographic isolation provides the opportunity for complete case capture in Nueces County of an acute disease such as stroke. There are 2 hospital systems representing 7 hospitals in Corpus Christi. All hospitals have computed tomography and magnetic resonance imaging (MRI) scanners and neurologists on staff. During the course of the study, 2 of the hospitals became Joint Commission Primary Stroke Centers. There are no medical schools or neurology training programs in the community.

Subjects are eligible for BASIC if they are 45 years or older and are residents of Nueces County, Texas at least 6 months per year. Ethnicity is defined by chart designation. We have previously reported excellent agreement (96.3\%) between self-report of ethnicity and chart designation. ${ }^{19}$ Only MA and NHW subjects were considered for this analysis due to very small numbers of other race/ethnicities. The project was approved by the University of Michigan Institutional Review Board (IRB) and the IRBs of both Nueces County hospital systems. A waiver of informed consent was obtained to screen and abstract charts. Written informed consent is obtained prior to subject interview.

\section{Case Ascertainment}

Procedures for complete case capture follow international recommendations for capture-recapture and multiple source ascertainment methods. ${ }^{20}$ Cases are primarily identified through active pursuit of emergency department and directly admitted stroke patients using validated screening terms. ${ }^{21}$ The abstractors also routinely canvass intensive care units and hospital floors searching for in-house strokes or those not ascertained through the screening logs. The active surveillance is supplemented by review of hospital passive listings of International Classification of Disease, 9th revision discharge codes for stroke (430-438; excluding 433.x0, 434.x0 $[\mathrm{x}=1-9]$; 437.0, 437.2, 437.3, 437.4, 437.5, 437.7, 437.8, and 438). County coroner records are screened for causes of sudden stroke death not presenting to the hospital. Several minor changes to case ascertainment procedures were made over the course of the project to maintain efficiency. In 2001, the following diagnostic terms were removed from the active surveillance list: dizziness, falling, imbalance, syncope, and trouble walking. These terms were found to be highly inefficient at identifying strokes, with a positive predict value of $\leq 1 \%$. Starting January 1, 2001, a sample of Nueces County primary care and cardiology offices, as well as $95 \%$ of neurologist offices, were contacted frequently and encouraged to report stroke cases to our project. Abstractors reviewed and abstracted cases not previously screened. The sampling of primary care physicians and cardiologists was subsequently discontinued on January 31, 2004, because during the 3 years of the sampling only 13 ischemic stroke patients were identified exclusively from this method of 1,866 ischemic stroke cases identified in BASIC. Because 74 cases from the sample identified came from neurology offices, we did continue to identify these few stroke cases from neurology offices. From January 31, 2004 to July 31, 2008, only 71 strokes were identified via the neurology office of 1,971 ischemic stroke cases identified. In 2008, we therefore stopped screening neurology offices. From January 1, 2000 through December 1, 2007, BASIC identified cases through active surveillance of both the admissions log and emergency department (ED) log. A review of this methodology in 2007 using complete data from calendar year 2004 suggested that frequent passive ED surveillance in combination with active surveillance of admission logs successfully identifies $\geq 98 \%$ of all ischemic strokes. This new methodology was implemented on December 2, 2007. Finally, we were unable to obtain passive listings of stroke from 1 of the hospital systems for 6 months of 2008. In other 6 -month periods, this 
never amounted to $>5$ cases. A sensitivity analysis was performed to determine the effects of the changes on incidence rate estimates and ethnic comparisons over time.

Cases are validated by neurologists or a stroke fellowshiptrained emergency medicine physician, blinded to subjects' ethnicity and age, using source documentation. Ischemic stroke diagnosis is based on published international clinical criteria ${ }^{20}$ that require onset of a focal neurologic deficit following a defined vascular distribution without documented resolution within 24 hours (unless treated with recombinant tissue plasminogen activator) and not explainable by a nonvascular etiology. Imaging is used to discriminate ischemic stroke and hemorrhagic stroke. Because the use of brain MRI has increased greatly in the past 10 years, validators are required to use the original clinical criteria for case validation, so that trend data can be assessed without bias. Therefore, subjects having acute infarction on brain MRI without the clinical deficit described above are validated as no stroke.

\section{Population Counts}

Population counts in 2000 and 2010 were obtained from the 2000 and 2010 Census. There were no significant changes in undercounting of Hispanic ethnicity or overcounting of NHW ethnicity in the US Census between 2000 and 2010, ${ }^{22}$ making it unlikely to affect trend estimates. There were only minor wording and formatting changes to how ethnicity was obtained in the 2000 and 2010 Census. $^{23}$ In 2000, 30\% of the Nueces County NHW and MA population was $\geq 45$ years of age, and this grew to $36 \%$ in 2010 . In the State of Texas, the corresponding numbers were $26 \%$ and $29 \% .^{24}$ Also, between 2000 and 2006, there were similar in-migration and out-migration of residents (taxpayers) at approximately $6.5 \% .^{25}$ Yearly population counts for 2001-2009 were obtained from intercensal estimates. ${ }^{26,27}$ Counts were aggregated by sex, race/ethnicity, and 3 age categories: 45 to 59,60 to 74 , and $\geq 75$ years. Counts for Hispanics, regardless of race, were used as the population at risk for MAs, because among the population aged $\geq 45$ years in Nueces County, only 2.6\% report ancestry from Spain, Central or South America, or Puerto Rico. ${ }^{28}$ Counts for NHWs only were used as the population at risk for NHWs because only $1 \%$ of the population aged $\geq 45$ years reported being white in combination with other races. ${ }^{26,27}$

\section{Quality Assurance}

Quality is ensured through several procedures, including rigorous abstractor training, certification, and periodic reliability testing of abstractors for screening. Validators are also trained and subject to periodic reliability and validity testing.

\section{Statistics}

Descriptive statistics for patient characteristics were calculated, and differences by ethnicity were assessed using chi-square and Kruskal-Wallis nonparametric tests for categorical and continuous variables, respectively. Crude annual ischemic stroke rates for the following outcomes were calculated per 10,000 population overall and by ethnicity: (1) first ever completed ischemic stroke (no documented past medical history of stroke in the medical record) and (2) first ever and recurrent completed ischemic stroke (all completed ischemic stroke events during BASIC regardless of reported past medical history before BASIC). The primary analysis was considered first ever completed ischemic stroke. Poisson regression models ${ }^{29}$ were used to calculate adjusted ischemic stroke rates, rate ratios, and trends over the years 2000-2010. Ischemic stroke (numerators) and population counts (denominators) for the models were aggregated within categories of ethnicity, age (45-59, 60-74, and $\geq 75$ years) and sex. Yearly ethnicity-, age-, and sexadjusted rates were calculated by treating time as a categorical variable, and including the adjustment factors as predictors. In separate models, time trends were modeled as a linear term representing years since 2000 to determine whether the trend in ischemic stroke rates was decreasing, increasing, or not changing significantly over time. For each outcome, an age-, sex-, and ethnicity-adjusted trend was estimated. Because prior work has shown that the magnitude of ethnic disparities differed by age, ${ }^{2}$ we prespecified fitting models stratified by age group (45$59,60-74$, and $\geq 75$ years), where we tested if the sex-adjusted trends over the 2000-2010 period differed by ethnicity by including an interaction term between time and ethnicity. When the trend did not differ significantly by ethnicity within each age group, the interaction between time and ethnicity was removed to provide a summary of the trend in ischemic stroke rate averaged across ethnicities, and to estimate the magnitude of the time-averaged ethnic disparity. A model combining all age groups, which included interactions between time and age categories and between ethnicity and age categories, was fitted to test for heterogeneity of time trends and ethnicity risk ratios by age. The online Supplementary Material provides details of the sensitivity analysis, illustrating the effects of changes in surveillance methodology over time.

\section{Results}

The total population of Nueces County, Texas was 313,512 in 2000 and 340,223 in 2010. Of the eligible population aged $\geq 45$ years, 45,984 MAs and 49,540 NHWs resided in the county in 2000. In 2010, there were 66,125 MAs and 55,779 NHWs. In BASIC, there were 40,783 screened events and 4,646 events validated as completed ischemic stroke in MAs and NHWs from January 1, 2000 through December 31, 2010. Results of the out-of-hospital surveillance program are available in the Supplementary Material. There were 2,604 ischemic strokes in MAs and 2,042 in NHWs, corresponding to 2,211 MA and 1,822 NHW unique individuals; 252 MAs and 156 NHWs had 2 strokes, 50 MAs and 23 NHWs had 3 strokes, and 13 MAs and 6 NHWs had $\geq 4$ strokes. Table 1 provides demographic and clinical information on the study subjects. MRI studies were obtained in $68.7 \%$ of MAs and $62.0 \%$ of NHWs $(p=0.0045)$.

Figure 1 shows the yearly sex-, age-, and ethnicityadjusted ischemic stroke rates and model-predicted trend 


\begin{tabular}{|c|c|c|c|c|}
\hline Characteristic & All, $n=4,033$ & $\mathrm{MA}, \mathrm{n}=2,211$ & NHW, $n=1,822$ & $p$ \\
\hline Age, yr, median (Q1, Q3) & $72.0(61,81)$ & $69.0(58,78)$ & $76.0(65,83)$ & $<0.001$ \\
\hline Sex, $\%$ female & 51.4 & 50.5 & 52.5 & 0.22 \\
\hline Race/ethnicity, \% MA & 54.8 & & & \\
\hline Atrial fibrillation, $\%$ & 14.9 & 10.4 & 20.4 & $<0.001$ \\
\hline Coronary artery disease, $\%$ & 33.3 & 32.8 & 34.0 & 0.43 \\
\hline Diabetes mellitus, $\%$ & 41.0 & 53.6 & 25.7 & $<0.001$ \\
\hline Excessive alcohol, \% & 5.9 & 6.3 & 5.3 & 0.16 \\
\hline High cholesterol, \% & 32.0 & 32.5 & 31.3 & 0.41 \\
\hline Hypertension, \% & 76.3 & 78.0 & 74.2 & 0.01 \\
\hline NIHSS, median (Q1, Q3) & $4(2,8)$ & $4(2,7)$ & $4(2,8)$ & 0.03 \\
\hline Smoking status, \% & & & & $<0.001$ \\
\hline Current & 19.2 & 18.7 & 19.8 & \\
\hline Former & 13.1 & 10.8 & 15.8 & \\
\hline Never & 67.7 & 70.4 & 64.4 & \\
\hline Any health insurance, $\%$ & 90.0 & 87.0 & 93.6 & $<0.001$ \\
\hline History of stroke or TIA, \% & 30.6 & 30.1 & 31.1 & 0.52 \\
\hline
\end{tabular}

lines for 2000-2010. Ischemic stroke rates declined significantly over this time period. The declines during the study period were $35.9 \%$ (95\% confidence interval [CI] $=25.9-44.5)$ for first ever completed ischemic stroke and $34.1 \%(95 \% \mathrm{CI}=25.5-41.6)$ for total first ever and recurrent completed ischemic stroke.

Figure 2 shows the sex- and age-adjusted (A) and age-specific (B-D), ethnic-specific yearly ischemic stroke rates and model-predicted trend lines for first ever completed ischemic stroke over the 2000-2010 period. The figure demonstrates the decline in ischemic stroke incidence, and preservation of the ethnic disparity in the younger age groups. Table 2 shows the model-predicted, sex-adjusted rates in 2000 and 2010 and the modelestimated trend during the study period by ethnicity and age group. Stroke rates have declined significantly in the $\geq 60$-year age groups but remained largely unchanged over time in those aged 45 to 59 years. The slope of the declining rates did not differ significantly by ethnicity in any age group (all $p$ values for ethnic difference in trend $>0.10$ ). Therefore, because the rates of decline over the study period are similar in both ethnic groups, the disparities seen in the 45- to 59and 60 - to 74-year age groups persist. Supplementary
Figure 3 demonstrates the yearly ischemic stroke counts and intercensal estimates.

Table 3 shows the rate ratios comparing MAs to NHWs across the age categories by outcome. The heterogeneity in rate ratios across age was statistically significant for both ischemic stroke rates $(p<0.001)$. The rate

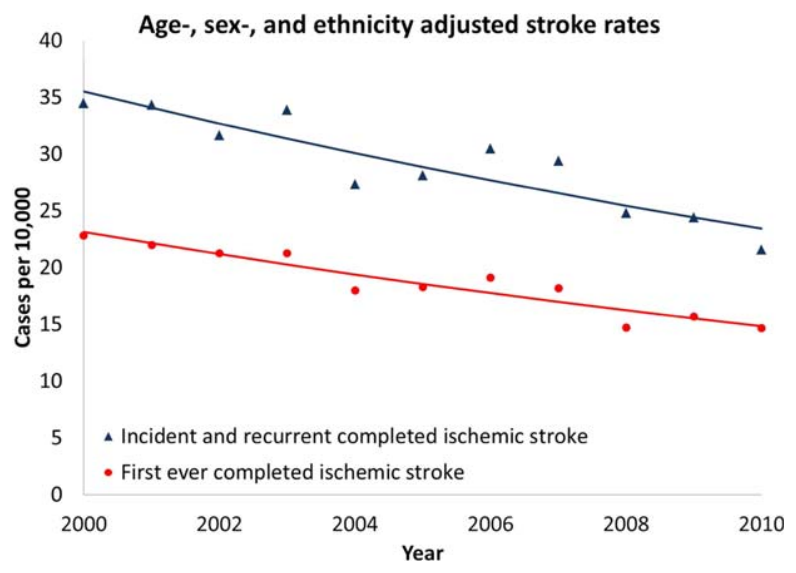

FIGURE 1: Age-, sex-, and ethnicity-adjusted completed ischemic stroke rates per 10,000 population, Nueces County, Texas, 2000-2010. See Supplementary Figure 1 for $95 \%$ confidence interval lines. [Color figure can be viewed in the online issue, which is available at www.annalsofneurology.org.] 
a)

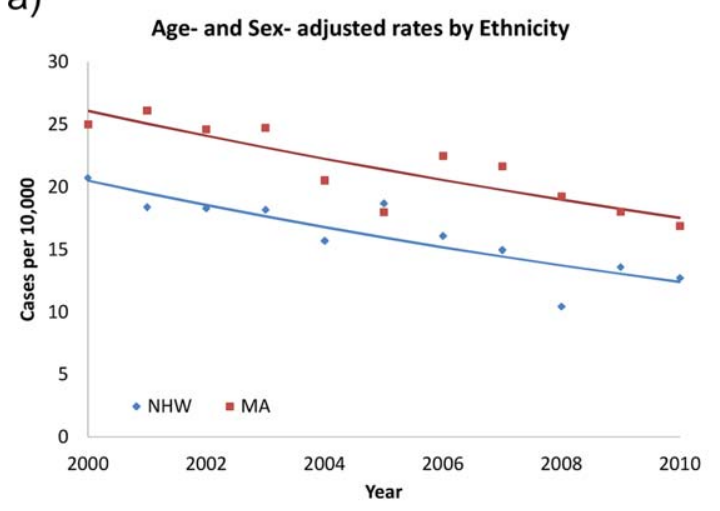

c)

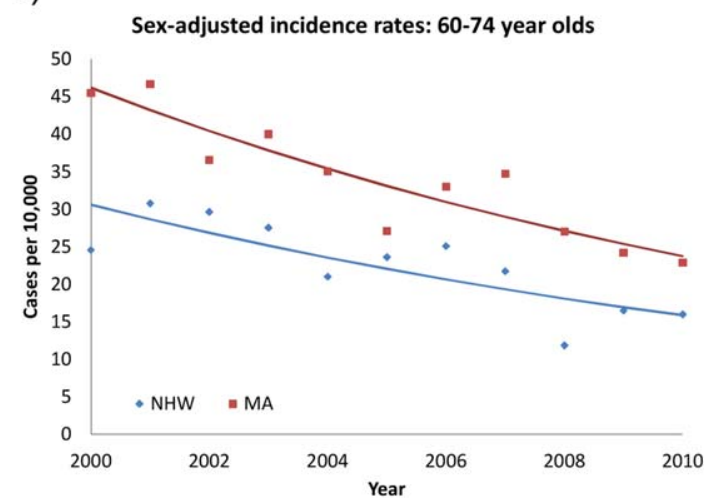

b)

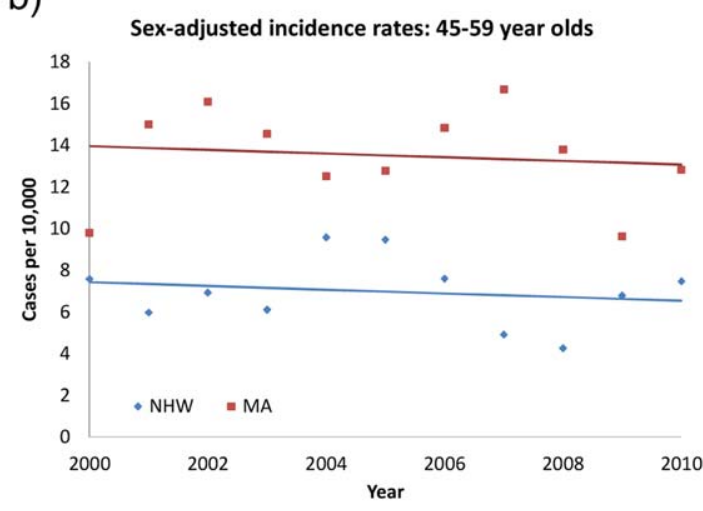

d)

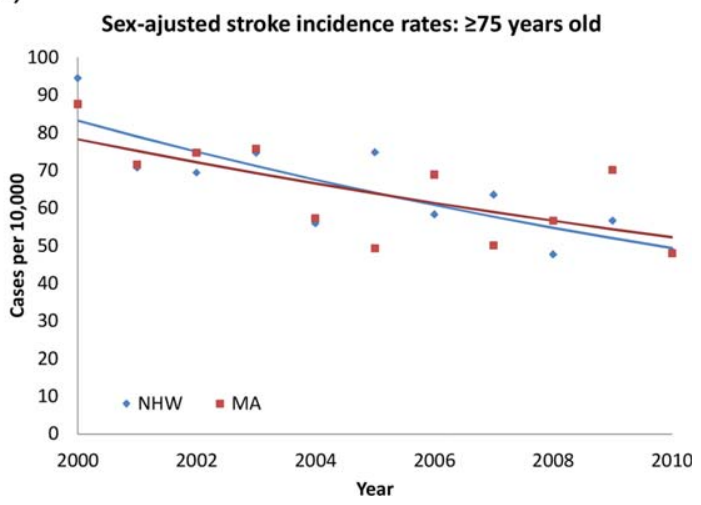

FIGURE 2: Sex-adjusted first ever completed ischemic stroke rates per 10,000 population by ethnicity, Nueces County, Texas, 2000-2010: (A) age-adjusted; (B) 45- to 59-year-olds; (C) 60- to 74-year-olds; (D) subjects $\geq 75$ years old. See Supplementary Figure 2 for $95 \%$ confidence interval lines. MA = Mexican American; NHW = non-Hispanic white. [Color figure can be viewed in the online issue, which is available at www.annalsofneurology.org.]

ratios for first ever ischemic stroke were $1.94(95 \% \mathrm{CI}$ $=1.67-2.25)$ among those aged 45 to 59 years, 1.50 $(95 \% \mathrm{CI}=1.35-1.67)$ among those aged 60 to 74 years, and $1.00(95 \% \mathrm{CI}=0.90-1.11)$ among those aged $\geq 75$ years. The age- and sex-adjusted rate ratio was $1.34(95 \% \mathrm{CI}=1.23-1.46)$. Similar results were found for total first ever and recurrent completed ischemic stroke, and the age- and sex-adjusted rate ratio was 1.40 $(95 \%$ CI $=1.29-1.52)$.

The results of the sensitivity analysis demonstrated that the changes in surveillance methods had negligible impact on the tests of differences in trends by ethnicity, the estimated ethnic differences, and the estimated trends (Supplementary Fig 4).

\section{Discussion}

This population-based study demonstrated the remarkable decrease in ischemic stroke incidence over an 11year period from 2000 to 2010 in MAs and NHWs. Rates of decline were similar among ethnic groups for all ages, and therefore disparities present in the year 2000 in the younger age groups (45-59 and 60-74) continued to persist through 2010. Although the declining ischemic stroke incidence in MAs and NHWs is encouraging, the persistent disparity in young stroke patients, who suffer the longest from poststroke disability, indicates a need for additional prevention efforts targeting young MAs and communities with large minority populations. The US Department of Health and Human Services recently published goals and objectives for reducing health disparities, ${ }^{30}$ although specific action plans remain elusive. Explanatory hypotheses regarding the MA-NHW ischemic stroke disparity are numerous and include an increased burden of cardiovascular risk factors in MAs. In the Hispanic Community Health Study, $80 \%$ of men and $71 \%$ of women had at least 1 cardiovascular risk factor. A previous community survey in Nueces County, Texas found a higher prevalence of diabetes in MAs but similar prevalence of other biological risk factors compared with NHWs. Education and income were less in MAs, as was the ability to recall stroke risk factors. MAs felt less confident in their ability to prevent stroke and more commonly cited cost as a barrier to stroke prevention. ${ }^{16}$ The current study found increased prevalence of 
TABLE 2. Ethnicity- and Age-Specific Completed Stroke Incidence Rate (per 10,000 Population) and Trend Comparison, Nueces County, Texas, 2000-2010

\begin{tabular}{|c|c|c|c|c|c|c|c|c|}
\hline \multirow[t]{2}{*}{ Stroke Group } & \multirow[t]{2}{*}{ Age, yr } & \multirow[t]{2}{*}{ Ethnicity } & \multicolumn{2}{|c|}{ Rate $^{a}$} & \multicolumn{2}{|c|}{ Trend: $2000-2010^{a}$} & \multicolumn{2}{|c|}{$p$} \\
\hline & & & 2000 & 2010 & $\%$ Change & $95 \% \mathrm{CI}$ & $\begin{array}{l}\text { Ethnic- } \\
\text { Specific } \\
\text { Trend }\end{array}$ & $\begin{array}{l}\text { Ethnic } \\
\text { Difference } \\
\text { in Trend }\end{array}$ \\
\hline \multirow[t]{2}{*}{ First ever } & $45-59$ & NHW & 7.4 & 6.5 & -11.9 & -40.5 to 30.3 & 0.52 & \\
\hline & $\begin{array}{l}60-74 \\
\geq 75 \\
45-59\end{array}$ & $\begin{array}{l}\text { MA } \\
\text { NHW } \\
\text { MA } \\
\text { NHW } \\
\text { MA } \\
\text { NHW }\end{array}$ & $\begin{array}{l}14.0 \\
30.6 \\
46.3 \\
83.2 \\
78.5 \\
10.0\end{array}$ & $\begin{array}{l}13.1 \\
15.9 \\
23.7 \\
49.7 \\
52.4 \\
9.2\end{array}$ & $\begin{array}{l}-6.3 \\
-48.2 \\
-48.8 \\
-40.2 \\
-33.3 \\
-8.1\end{array}$ & $\begin{array}{l}-28.6 \text { to } 22.9 \\
-62.1 \text { to }-29.2 \\
-56.0 \text { to }-40.3 \\
-50.4 \text { to }-28.0 \\
-50.6 \text { to }-9.9 \\
-31.4 \text { to } 23.1\end{array}$ & $\begin{array}{l}0.64 \\
<0.001 \\
<0.001 \\
<0.001 \\
0.01 \\
0.57\end{array}$ & $\begin{array}{l}0.80 \\
0.95 \\
0.54\end{array}$ \\
\hline $\begin{array}{l}\text { First ever }+ \\
\text { recurrent }\end{array}$ & $\begin{array}{l}60-74 \\
\geq 75\end{array}$ & $\begin{array}{l}\text { MA } \\
\text { NHW } \\
\text { MA } \\
\text { NHW } \\
\text { MA }\end{array}$ & $\begin{array}{l}21.9 \\
50.7 \\
76.4 \\
129.1 \\
148.9\end{array}$ & $\begin{array}{l}18.8 \\
24.2 \\
42.2 \\
97.3 \\
93.7\end{array}$ & $\begin{array}{l}-14.2 \\
-52.3 \\
-44.8 \\
-24.7 \\
-37.1\end{array}$ & $\begin{array}{l}-30.9 \text { to } 6.5 \\
-63.3 \text { to }-37.9 \\
-54.1 \text { to }-33.6 \\
-36.6 \text { to }-10.5 \\
-45.2 \text { to }-27.7\end{array}$ & $\begin{array}{l}0.16 \\
<0.001 \\
<0.001 \\
0.001 \\
<0.001\end{array}$ & $\begin{array}{l}0.71 \\
0.38 \\
0.11\end{array}$ \\
\hline
\end{tabular}

diabetes and hypertension but less atrial fibrillation in MA compared with NHW stroke patients. A focus on risk factors that are especially prevalent in minority populations, such as diabetes, which is more common in Hispanics/Latinos and an important stroke risk factor, may be a way of reducing stroke disparities. ${ }^{31}$

Studies from around the world have documented declining stroke incidence, including a $40 \%$ decline over 23 years ending in 2004 from the Oxfordshire Community Stroke Project. ${ }^{6}$ A similar $19 \%$ reduction in stroke incidence was seen during a 22-year period in an Auckland community surveillance project ending in 2003 . $^{7}$ Declines in stroke incidence have also been noted in $\mathrm{Japan}^{8}$ and in men but not women in the Netherlands. In the United States, the Framingham Project documented a 20 to $30 \%$ decline over 50 years ending in $2004 .^{10}$ It is encouraging that the current study suggests that the declines in stroke incidence are continuing in the 11-year period ending in 2010 and extend to MAs, an important population not included in previous reports. The lack of a significant decline in stroke incidence over time in those aged 45 to 59 years (see Fig 2B), which is supported by similar work suggesting rising stroke risk in those aged 20 to 54 years in the Greater Cincinnati/Northern Kentucky Stroke Study, ${ }^{5}$ suggests the need for renewed efforts to target young individuals with stroke risk.

Studies documenting trends in stroke disparities are few. The South London Stroke Registry showed an approximate overall $20 \%$ incidence reduction in a 10 -year period ending in 2004. In black women, a remarkable $52 \%$ decline in incidence rate was observed, but no change was seen in black men, and overall black-white disparities persist in South London. ${ }^{11}$ The Greater Cincinnati/Northern Kentucky Stroke Study demonstrated a reduction in stroke incidence in whites but not African Americans, suggesting

\section{TABLE 3. RRs Comparing MA with NHW Completed Ischemic Stroke, Nueces County, Texas, 2000-2010}

\begin{tabular}{|c|c|c|c|c|}
\hline \multirow[t]{2}{*}{ Stroke Group } & \multirow[t]{2}{*}{ Age, yr } & \multicolumn{3}{|c|}{ MA vs NHW } \\
\hline & & $\mathbf{R R}$ & & CI \\
\hline \multirow[t]{3}{*}{ First ever ${ }^{a}$} & $45-59$ & 1.94 & 1.67 & 2.25 \\
\hline & $60-74$ & 1.50 & 1.35 & 1.67 \\
\hline & $\geq 75$ & 1.00 & 0.90 & 1.11 \\
\hline \multirow{3}{*}{$\begin{array}{l}\text { First ever and } \\
\text { recurrent }^{\mathrm{a}}\end{array}$} & $45-59$ & 2.11 & 1.88 & 2.37 \\
\hline & $60-74$ & 1.61 & 1.47 & 1.76 \\
\hline & $\geq 75$ & 1.06 & 0.97 & 1.15 \\
\hline
\end{tabular}


a widening of the black-white stroke disparity gap in that community. ${ }^{12}$

The current study has several strengths, including its population-based approach in a geographically isolated, urban community without tertiary referral bias; few changes to surveillance procedures over the years and a sensitivity analysis to examine the influence of those changes; a multiethnic, nonimmigrant community with little influx and efflux of residents; rigorous case ascertainment; a consistent validation algorithm; and a stable group of investigators and abstractors over time. The study also has several limitations, including a focus on 1 community in South Texas, making the ability to generalize the findings potentially problematic; the choice of a community with ample representation of MAs but not enough African Americans to quantify incidence trends in that important US population; and the increased use of MRI, which may influence physician charting and therefore our abstraction, although MRI was not considered for ischemic stroke case validation purposes. Furthermore, although Corpus Christi does not have a predominantly immigrant population, and all sources suggest very low numbers of undocumented residents particularly among those aged $\geq 45$ years, it is impossible to accurately quantify undocumented residents.

In summary, this study suggests declining ischemic stroke incidence in MAs and NHWs with a persistent ethnic stroke disparity in those $<75$ years of age. A reinvigorated effort to reduce this disproportionate stroke burden in MAs should ensue.

\section{Acknowledgment}

This study was funded by NIH NINDS R01NS38916, NHLBI R01HL098065, and NINDS R01NS070941. D.B.Z. is supported by NIH NIA K23AG038731, and L.E.S. is funded by NIH NINDS K23NS073685. Travel support was provided by the NIH National Institute of Neurological Disorders and Stroke/American Neurological Association (L.E.S., W.J.M.).

\section{Potential Conflicts of Interest}

D.L.B.: grants/grants pending, CVR Global; honoraria, Wayne State University, American Academy of Neurology. W.J.M.: grants/grants pending, AHRQ, NIHNINDS/FDA; academic emergency medicine methodology statistics reviewer.

\section{References}

1. US Census Bureau.Profile America facts for features. Available at: http://www.census.gov/newsroom/releases/archives/facts_for_ features special editions/cb12-ff19.html Accessed January 3, 2013.

2. Morgenstern LB, Smith MA, Lisabeth LD, et al. Excess stroke in Mexican Americans compared with non-Hispanic whites: the Brain Attack Surveillance in Corpus Christi Project. Am J Epidemiol 2004;160:376-383

3. Brown DL, Boden-Albala B, Langa KM, et al. Projected costs of ischemic stroke in the United States. Neurology 2006;67:13901395.

4. Statistics of Income Division, Internal Revenue Service.2011 tax statistics. Available at: http://www.irs.gov/pub/irs-soi/11taxstatscard. pdf Accessed January 24, 2013.

5. Kissela BM, Khoury JC, Alwell K, et al. Age at stroke: temporal trends in stroke incidence in a large, biracial population. Neurology 2012;79:1781-1787.

6. Rothwell PM, Coull AJ, Giles MF, et al. Change in stroke incidence, mortality, case-fatality, severity, and risk factors in Oxfordshire, UK from 1981 to 2004 (Oxford Vascular Study). Lancet 2004; 363:1925-1933.

7. Carter K, Anderson C, Hacket M, et al. Trends in ethnic disparities in stroke incidence in Auckland, New Zealand, during 1981 to 2003. Stroke 2006;37:56-62.

8. Kubo M, Hata J, Doi $Y$, et al. Secular trends in the incidence of and risk factors for ischemic stroke and its subtypes in Japanese population. Circulation 2008;118:2672-2678.

9. Wieberdink RG, Ikram MA, Hofman A, et al. Trends in stroke incidence rates and stroke risk factors in Rotterdam, the Netherlands from 1990 to 2008. Eur J Epidemiol 2012;27:287-295.

10. Carandang R, Seshadri S, Beiser A, et al. Trends in incidence, lifetime risk, severity, and 30-day mortality of stroke over the past 50 years. JAMA 2006;296:2939-2946.

11. Heuschmann PU, Grieve AP, Toschke AM, et al. Ethnic group disparities in 10-year trends in stroke incidence and vascular risk factors: the South London Stroke Register (SLSR). Stroke 2008;39: 2204-2210

12. Kleindorfer DO, Khoury J, Moomaw CJ, et al. Stroke incidence is decreasing in whites but not in blacks: a population-based estimate of temporal trends in stroke incidence from the Greater Cincinnati/Northern Kentucky Stroke Study. Stroke 2010;41:1326-1331.

13. Piriyawat $\mathbf{P}$, Smajsova $\mathrm{M}$, Smith $\mathrm{MA}$, et al. Comparison of active and passive surveillance for cerebrovascular disease: the Brain Attack Surveillance in Corpus Christi (BASIC) Project. Am J Epidemiol 2002;156:1062-1069.

14. Smith MA, Risser JM, Moye LA, et al. Designing multi-ethnic stroke studies: the Brain Attack Surveillance in Corpus Christi (BASIC) project. Ethn Dis 2004;14:520-526.

15. US Census Bureau.State and County Quick Facts: Nueces County Texas. Available at: http://quickfacts.census.gov/gfd/states/ 48/48355.html Accessed January 24, 2013.

16. Morgenstern LB, Steffen-Batey L, Smith MA, Moye LA. Barriers to acute stroke therapy and stroke prevention in Mexican Americans. Stroke $2001 ; 32: 1360-1364$

17. Nelsen A, Buch J.Immigrant wave pours into South Texas Available at: http://www.mysanantonio.com/news/local_news/ article/Wave-of-migrants-pours-into-S-Texas-4433001.php Accessed June 3, 2013

18. University of Texas at Austin, Division of Statistics + Scientific Computation.Applied demography: some Texas examples. Slide 31. Available at: http://txsdc.utsa.edu/Resources/Presentations/ OSD/2013/2013_02_06_Statistics_in_Action.pdf Accessed May 21, 2013.

19. Caveney AF, Smith MA, Morgenstern LB, Lisabeth LD. Use of death certificates to study ethnic-specific mortality. Public Health Rep 2006;121:275-281. 
20. Asplund K, Tuomilehto J, Stegmayr B, et al. Diagnostic criteria and quality control of the registration of stroke events in the MONICA project. Acta Med Scand Suppl 1988;728:26-39.

21. Morgenstern LB, Wein TH, Smith MA, et al. Comparison of stroke hospitalization rates among Mexican-Americans and non-Hispanic whites. Neurology 2000;54:2000-2002.

22. US Census Bureau.Census Bureau releases estimates of undercount and overcount in the 2010 Census. Available at: http://www.census.gov/newsroom/releases/archives/2010_census/ cb12-95.html Accessed May 24, 2013.

23. Ennis S, Ríos-Vargas M, Albert NG. The Hispanic population: 2010. Monograph. Washington, DC: US Census Bureau, 2011.

24. US Census Bureau.National intercensal estimates (2000-2010) Available at: http://www.census.gov/popest/data/intercensal/ national/nat2010.html Accessed June 11, 2013

25. City-Data.com.Nueces County, Texas (TX). Available at: http://www.city-data.com/county/Nueces_County-TX.html Accessed June 11, 2013.
26. US Census Bureau.Population estimates. Available at: http://www. census.gov/popest/data/counties/asrh/2009/CC-EST2009-alldata. html Accessed January 26, 2013

27. US Census Bureau.Population estimates. Available at: http://www. census.gov/popest/data/counties/asrh/2011/CC-EST2011-alldata. html Accessed January 26, 2013.

28. US Census Bureau.American fact finder. Available at: http:// factfinder2.census.gov/faces/nav/jsf/pages/index.xhtml Accessed January 26, 2013.

29. Lachin JM. Biostatistical methods: the assessment of relative risks. 2nd ed. Hoboken, NJ: John Wiley \& Sons, 2011.

30. US Department of Health and Human Services National Partnership for Action to End Health Disparities. Available at: http://minorityhealth.hhs.gov/npa/templates/content.aspx?|v|=1\&|vlid=33\&ID=286 Accessed January 24, 2013.

31. Daviglus ML, Talavera GA, Aviles-Santa ML, et al. Prevalence of major cardiovascular risk factors and cardiovascular diseases among Hispanic/Latino individuals of diverse backgrounds in the United States. JAMA 2012;308:1775-1784. 